\title{
Políticas de formação de professores no Brasil: desdobramentos e interlocução com diretrizes dos organismos internacionais
}

\section{Teacher education policy in Brazil: understanding and interlocation with guidelines from international organizations}

\section{Políticas de formación de profesores en Brasil: desdoblamientos e interlocución con las directrices de los organismos internacionales}

\author{
Marilene Gabriel Dalla Corte ${ }^{1}$ \\ Universidade Federal de Santa Maria, Professora Adjunta no Departamento de Administração \\ Escolar do Centro de Educação \\ Rosane Carneiro Sarturi² \\ Universidade Federal de Santa Maria, professora Associada II no Departamento de \\ Administração Escolar \\ Janilse Fernandes Nunes ${ }^{3}$ \\ Centro Universitário Franciscano
}

Resumo: No texto analisam-se as políticas de formação dos professores no Brasil em seus desdobramentos e recomendações de organismos internacionais. $\mathrm{O}$ artigo é fruto de pesquisa bibliográfica e documental, à luz de marcos teóricos e legais que subsidiam reflexões acerca das prioridades, orientações e programas de governo subjacentes à formação de professores. Entre os principais resultados, destacam-se: as reformas educacionais observam as recomendações dos organismos internacionais; as políticas educativas atuais reafirmam a centralidade da formação para o/no exercício da docência; os programas de formação estão relacionados à natureza das funções docentes; e as instituições formadoras atuam como

\footnotetext{
Doutora em Educação pela Pontifícia Universidade Católica do Rio Grande do Sul; Mestre em Educação pela Universidade Federal de Santa Maria.

2 Pós-doutora em Políticas Públicas na Universidade de Valência; Doutora em Educação pela Universidade Federal do Rio Grande do Sul.

3 Doutora em Educação pela Universidade Federal de Santa Maria, com período sanduíche na Faculdade de Educação, na Universidade de Sevilha, Espanha; Mestre em Educação pela Universidade do Vale do Rio dos Sinos.
} 
mecanismos para atender às demandas de processos produtivos e performativos oriundos da lógica global.

Palavras-chave: Políticas públicas. Formação de professores. Organismos internacionais.

Abstract: The text analyzes the policies of teacher training in Brazil in its developments and recommendations from international organizations. It is the result of bibliographical and documentary research, in the light of theoretical and legal frameworks that subsidize reflections about the priorities, orientations and government programs that underlie teacher training. Among the main results, it is worth noting: educational reforms follow the recommendations of international organizations; The current educational policies reaffirm the centrality of the training for the / in the teaching practice; The training programs are related to the nature of the teaching functions and the training institutions act as mechanisms to meet the demands of productive and performative processes from the global logic.

Keywords: Public policies. Teacher training. International organizations.

Resumen: El texto analiza las políticas de formación de los profesores en Brasil en sus desdoblamientos y recomendaciones de los organismos internacionales. Es fruto de investigación bibliográfica y documental, a la luz de los marcos teóricos y legales que subsidian reflexiones acerca de prioridades, orientaciones y programas de gobierno subyacentes a la formación de los profesores. Entre los resultados principales, destacase: reformas educacionales que observan recomendaciones de los organismos internacionales; politicas educativas actuales reafirman la centralidad de la formación para el/en ejercicio de la docencia; programas de formación están relacionados a la naturaleza de las funciones docentes y las instituciones formadoras actúan como mecanismos para atender las demandas de los procesos productivos y performativos oriundos de la lógica global.

Palabras clave: Politicas públicas. Formación de profesores. Organismos internacionales.

\section{DISCUSSÕES INICIAIS}

As políticas educacionais brasileiras constantemente têm passado por (re)formulações e (re)articulações com base nas orientações e recomendações de múltiplos organismos internacionais. Destacam-se neste estudo o Banco Mundial, a 
UNESCO,${ }^{4}$ a $\mathrm{OECD}^{5}$ e as Conferências/Fóruns Mundiais de Educação relacionadas/ os à qualificação dos profissionais da educação.

Nos últimos anos, especialmente a partir da década de 1990, as (re) formulações educativas no Brasil vêm objetivando criação e maior articulação do sistema educacional à qualidade da oferta dos serviços educacionais, assumindo como centralidade a formação dos profissionais da educação (inicial e continuada) para desencadear (re)estruturação no modelo econômico do País e, consequentemente, mudança na área da economia. Para Nogueira (2003, p. 22), as políticas relacionadas à formação de professores a contar de 1995, “[...] tem como objetivo central ajustar o perfil do professor e a formação docente às demandas do novo mercado de trabalho, em um período marcado por novos padrões de produção, no interior da reestruturação da forma de acumulação capitalista."

Considerando a perspectiva das reformas de estado e de governo, visualiza-se que a educação tem se vinculado à lógica do capital e, portanto, às demandas do mercado. Os trabalhadores da educação, nessa lógica, são centralidade porque constituem-se fator

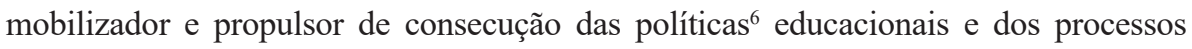
formativos tanto na educação básica quanto na educação superior e, nesse sentido, tais políticas priorizam, segundo Nogueira (2003), adequar a escola e a universidade à hegemonia da acumulação de capital. Também, nessa lógica, encontram-se desafios constantes às instituições escolares e universitárias, entre eles: a flexibilização curricular, a educação a distância, as novas arquiteturas a partir da diversificação das instituições e seus cursos, a interlocução entre a educação básica e superior, inclusão e equidade social, diversificação das fontes de financiamento, entre outros, que demandam o desenvolvimento de estratégias educacionais inter-relacionadas ao dicotômico mercado de trabalho que necessita de profissionais versáteis, modernos, criativos e inovadores,

\footnotetext{
4 A Organização das Nações Unidas para a Educação, a Ciência e a Cultura (Unesco), organismo internacional que representa as Nações Unidas, foi fundada em 1945. Objetiva contribuir com ações educacionais no mundo inteiro, no sentido de veicular paz e segurança aos cidadãos. Voltada para a minimização do analfabetismo no mundo, prioriza essencialmente a formação e a qualificação de professores.

5 A OCDE foi criada em 1961, na França. É intitulada Organização para a Cooperação e Desenvolvimento Econômico e sua representatividade tem 30 países agregados e envolvidos com o desenvolvimento econômico, com a sustentabilidade, com alternativas de geração de novos empregos, aumento da qualidade de vida, assim como a contribuição para o crescimento do comércio mundial.

6 Políticas educacionais: "fazem parte do conjunto de políticas públicas sociais, expressão da ação (ou não-ação) social do Estado e que têm como principal referente a máquina governamental no movimento de regulação do setor de educação. Elas expressam os referenciais normativos subjacentes às políticas e que podem se materializar nas distintas filosofias de ação. Neste processo interagem distintos atores sociais e as ações são explicitadas através de programas." (AZEVEDO; AGUIAR, 2001, p. 74-75).
} 
mas que ainda é regido pela concepção técnico-científica, performativa e gerencialista de atuação profissional (BALL, 2010a; 2010b).

Tais desafios e pressupostos estão engendrados ao discurso de democratização da educação e da necessidade de aumentar a escolarização da população nos países não desenvolvidos e emergentes, desencadeando um processo de aligeiramento da formação básica e da formação inicial em nível superior, bem como um processo de certificação institucional docente e discente em larga escala que, muitas vezes, não condiz com a tão esperada e necessária qualidade educacional.

Nessa lógica, as (re)formulações educacionais que foram realizadas em nível mundial, a partir da década de 1990 e em andamento nos anos 2000, estão alocadas nas demandas do capital mundial configurando-se, sobretudo, pela diminuição do papel do Estado e responsabilização, em nome da democratização, das múltiplas esferas públicas e privadas. São reformas e mudanças instauradas pelo fenômeno da globalização e da era tecnológica, requerendo maior e melhor eficiência e eficácia, bem como desempenho profissional consubstanciado em ciência, conhecimento generalista e ao mesmo tempo específico, bem como níveis de complexidade digital, repercutindo em "produtividade" exacerbada, muitas vezes entendido de maneira equivocada no contexto das universidades, principalmente, pelo fenômeno do produtivismo acadêmico.

É nessa lógica da sociedade globalizada que os últimos governos no Brasil vêm priorizando a elaboração de políticas de formação dos profissionais da educação, com a finalidade de desencadear a adequação do trabalho docente às novas exigências do mercado e das metas do capital mundial. Por meio de recomendações, que indicam uma série de orientações aos diferenciados blocos econômicos, os organismos internacionais têm produzido/induzido os países a se (re)articularem quanto à proposição e consecução de políticas sociais, nesse caso educacionais, que priorizam o desenvolvimento social e econômico de tais contextos.

Assim, este estudo está relacionado a uma pesquisa de cunho bibliográfico e documental que objetiva analisar políticas e programas no campo da formação docente no Brasil, na perspectiva de analisar as principais diretrizes mundiais e prioridades de qualificação dos profissionais da educação, em seus desdobramentos e recomendações/orientações de organismos internacionais. 


\section{ORGANISMOS INTERNACIONAIS E (RE)FORMULAÇÕES EDUCACIONAIS NA FORMAÇÃO DOS PROFISSIONAIS DA EDUCAÇÃO NO BRASIL}

No Brasil, encontram-se disponíveis os estudos de Evangelista, Moraes e Shiroma (2002), Silva Júnior (2002), Maciel e Neto (2004), Campos (2002), Maués (2009), Ball (2010a; 2010b), Dalla Corte e Sarturi (2015a; 2015b), entre outros, que apresentam análises acerca da influência de organismos internacionais nas (re) formulações de políticas públicas educacionais brasileiras, entre eles, as principais orientações decorrentes do Banco Mundial e da Unesco e, também, as recomendações da OCDE quanto à formação de professores na atualidade, além de Conferências e Fóruns Mundiais de Educação.

As (re)formulações das políticas sociais, em especial as educacionais, a partir da década de 1990 são entendidas pelos estudiosos da área como o divisor de águas para a era da "ideologia neoliberal” no Brasil. Tais políticas neoliberais, a partir da década de 1980, já estavam sendo disseminadas no continente Latino Americano.

Conforme Maciel e Neto (2004, p. 36), o neoliberalismo constitui-se “[...] um projeto político, econômico e social de caráter hegemônico que está fundamentado na subordinação da sociedade ao mercado livre e a não intervenção do poder público [...]” Neste sentido, no Brasil, a partir da década de 1990, “[...] deflagrou-se o processo de ajuste da economia brasileira às exigências da reestruturação global da economia." (EVANGELISTA; MORAES; SHIROMA, 2002, p. 55). As (re)formulações das políticas públicas sociais passaram a ser defendidas pelo governo brasileiro com base em um modelo de discurso democrático e voltado para a superação de problemas sociais, em que a reforma política alicerçada na redefinição do papel do Estado passou a gerar (re)configuração da concepção e organização da educação.

Considerando a crise do governo Collor, teve início o governo de Itamar Franco, passando a implantar uma reforma educacional ancorada especialmente nos preceitos e acordos decorrentes da Conferência de Jomtien, ${ }^{7}$ Conferência Mundial

\footnotetext{
Conferência promovida pela ONU em 1990 na Tailândia, em que 155 nações assumiram o compromisso de assegurar educação básica de qualidade para crianças, jovens e adultos. A conferência ancorou-se em indicadores referentes ao quantitativo de mais de 100 milhões de pessoas no mundo sem acesso à escola e, destas, 60 milhões eram mulheres; 900 milhões de analfabetos com idade acima de 15 anos; fracasso e evasão escolar, entre outros indicativos dos problemas que envolvia a educação.
} 
de Educação para Todos. Nessa Conferência foi aprovada a "Declaração Mundial de Educação para Todos", contendo 10 artigos referentes ao direito de todos à educação básica e aos deveres das nações para com as necessidades básicas de aprendizagem, configurando-se como uma Conferência de articulação e difusão das políticas educacionais internacionais, impulsionando vários países no cenário mundial a (re) formular sua legislação educacional e (re)construir seus Planos de Educação com base nos preceitos e prioridades da Conferência.

No art. 7 da Declaração Mundial de Educação para Todos, de 1990, que se refere a "fortalecer as alianças", consta:

[...] Novas e crescentes articulações e alianças serão necessárias em todos os níveis: entre todos os sub-setores e formas de educação, reconhecendo o papel especial dos professores, dos administradores e do pessoal que trabalha em educação; entre os órgãos educacionais e demais órgãos de governo, incluindo os de planejamento, finanças, trabalho, comunicações, e outros setores sociais; entre as organizações governamentais e não-governamentais, com o setor privado, com as comunidades locais, com os grupos religiosos, com as famílias. É particularmente importante reconhecer o papel vital dos educadores e das famílias. Neste contexto, as condições de trabalho e a situação social do pessoal docente, elementos decisivos no sentido de se implementar a educação para todos, devem ser urgentemente melhoradas em todos os países signatários da Recomendação Relativa à Situação do Pessoal Docente OIT/UNESCO [...] (UNESCO, 1990, p. 5, grifo nosso).

Em síntese, essa Conferência difundiu e fortaleceu a ideia de que a educação de qualidade para atender as necessidades básicas de aprendizagem das crianças, dos jovens e dos adultos, torna-se necessário um conjunto de medidas que contribuam para acesso, permanência e sucesso escolar, entre elas atenção à formação e atuação dos professores.

No ano 2000, no Fórum Mundial de Dakar, países membros da Unesco, que se comprometeram a reafirmar/ampliar as metas de educação para todos de Jomtien, assinaram o Marco de Ação de Dakar Educação Para Todos. Nesse documento, consta o comprometimento dos governos, organizações, agências, grupos e associações representadas na Cúpula Mundial de Educação quanto a "[...] melhorar o status, a auto-estima e o profissionalismo dos professores." (UNESCO, 2000, p. 2). Assim, países incluindo o Brasil assumiram a necessidade de priorizar a valorização e 
qualificação dos professores e tais orientações e preceitos desencadearam em diversos países, no mundo inteiro, (re)formulações em suas políticas educacionais.

No ano 2015, com base no legado de Jomtien e Dakar, a Declaração decorrente do Fórum Mundial realizado em Incheon reforçou o compromisso, as prioridades e as metas educacionais dos países membros da Unesco, voltados para a qualidade e "[...] transformação de vidas por meio de uma nova visão para a educação, com ações ousadas e inovadoras, para que alcancemos nossa ambiciosa meta até 2030." (UNESCO, 2015, p. 4). Encontra-se nesse texto elementos constituintes de uma agenda de educação coletiva que requer dos países membros o desenvolvimento de políticas públicas e planejamento sólidos, assim como sejam firmados acordos de cooperação técnica eficientes e de qualidade.

Ao reconhecer a parceria global para a educação, os países participantes do Fórum sinalizaram na Declaração que o papel da Unesco continue,

[...] designado de liderar e coordenar a agenda de educação 2030, em particular ao assumir a defesa da manutenção do compromisso político; facilitar o diálogo político, o compartilhamento de conhecimento e o estabelecimento de padrões; monitorar o progresso para a realização das metas educacionais; convocar as partes interessadas no âmbito global, regional e nacional a orientar a implementação da agenda; e funcionar como ponto focal para educação na estrutura geral de coordenação dos ODS. (UNESCO, 2015, p. 5).

No que dizrespeitoà formação e atuação dos profissionais da educação, consta no texto o seguinte: "Garantiremos que professores e educadores sejam empoderados, recrutados adequadamente, bem treinados, qualificados profissionalmente, motivados e apoiados em sistemas que disponham de bons recursos e sejam eficientes e dirigidos de maneira eficaz", de acordo com a Declaração de Incheon (UNESCO, 2015, p. 2). Assim, rumo a uma educação de qualidade inclusiva e equitativa e à educação ao longo da vida para todos, tornou-se cada vez mais premente o investimento na formação de qualidade e permanente dos professores.

O Brasil vem priorizando atender aos compromissos de Jomtien (1990), Dakar (2000) e Incheon (2015), por meio de (re)formulações das políticas educacionais brasileiras que observaram as principais orientações e recomendações dos organismos internacionais, no sentido de congregar com a comunidade mundial em termos de prioridades educacionais, bem como alinhar o País as exigências do mercado global. Silva Júnior (2002, p. 206) discute essa lógica: “As reformas educacionais na América 
Latina, particularmente no Brasil, são uma intervenção consentida realizada pelas autoridades educacionais nos moldes das agências multilaterais, no contexto da universalização do capitalismo [...]" Campos (2004, p. 2) menciona que os analistas dos organismos internacionais afirmavam acerca da " "...] existência de um descompasso entre a educação oferecida pelos sistemas educacionais e as necessidades do mercado do trabalho [...]"

De acordo com orientações do Banco Mundial, ${ }^{8}$ encontradas em um documento relacionado ao setor da educação, intitulado Prioridades y Estrategias para la Educacion, verifica-se a indicação de prioridades necessárias para a área da educação:

1. Dar más prioridad a la educaión. 2. Prestar más atención a los resultados. 3. Centrar la inversión pública em la enseñanza básica, recurriendo al mismo tiempo em mayor medida al financiamiento familiar para la enseñanza superior. 4. Prestar más atención a la equidad. 5. Dar más participación al grupo familiar. 6. Dar más autonomia a las instituciones. (BANCO MUNDIAL, 1995, p. XXII-XXVI, grifo nosso).

Tal documento está centrado na importância da educação básica para o funcionamento e desenvolvimento da sociedade. Além dessas orientações do Banco Mundial repercutirem em especial nos anos iniciais do Ensino Fundamental, o investimento na formação dos profissionais que atuam nesse nível da educação tornou-se sinônimo de educação básica de qualidade no Brasil. Tal conclusão, justifica-se, entre outros elementos, pelas orientações atribuídas pelo Banco Mundial quando pontuou que seriam necessários professores qualificados para atuação na docência, o que se traduz em " [...] contratar personal debidamente capacitado cuyos conocimientos se hayan evaluado.” (BANCO MUNDIAL, 1995, p. 91). Também, cabe destacar que nesse documento são priorizados o acesso, a qualidade, a equidade e a aceleração das reformas, apontando a importância da distribuição equitativa dos recursos destinados à educação. Apesar de não apontar como centralidade o professor, torna-se impossível fragmentar esse processo de gestão do processo educativo sem investimento nos recursos humanos.

\footnotetext{
8 Os documentos lançados pelo Banco Mundial objetivam encaminhar orientações acerca de prioridades nas áreas sociais e de políticas públicas aos países que se utilizam dos empréstimos desse organismo internacional.
} 
Entre as recomendações do BM quanto à distribuição de recursos, está a necessidade de investimento na capacitação docente e na contratação de professores que possuem formação e domínio nas diversas áreas de conhecimentos (BANCO MUNDIAL, 1995). Além disso, encontram-se recomendações acerca do número de alunos por professor, das provas de seleção e avaliação de professores, da necessidade de o professor possuir autonomia associada a um plano curricular nacional. Segundo o Banco Mundial, todos esses elementos são fatores intervenientes na qualificação da educação básica.

Em 2005, o Banco Mundial publicou outro documento intitulado Mejorar la enseñanza y el aprendizaje por medio de incentivos, em que o professor se constitui temática prioritária. Nas recomendações constam a importância do professor, assim como dos incentivos e da valorização profissional. Para o BM, incentivo se refere a "[...] algo que despierta um sentimiento o incita a la acción; uma causa o motivo de entusiasmo; uma incitación, provocación" (BANCO MUNDIAL, 2005, p. 7), ou seja, políticas e estratégias utilizadas para captar professores e, também, trabalhar com a motivação daqueles em serviço. Tais políticas de formação de professores são voltadas para melhorar a qualidade da educação ofertada.

Conforme o Banco Mundial (2005), são pelo menos sete elementos que influenciam na qualidade do ensino: os professores têm de ter acesso aos materiais didáticos adequados e contar com boa infraestrutura física nas escolas, incluindo a necessidade de adequação dos materiais e espaço físico à faixa etária do estudante; que os professores tenham consciência da sua importância junto aos estudantes e que estejam preparados para a jornada de trabalho; o processo de contratação de professores requer seguir critérios de maior formação, atuação e desempenho profissional; a necessidade de os professores acompanharem e analisarem os resultados dos investimentos em educação; a necessidade de formação e avaliação contínua para os docentes; a importância da eficiência e da eficácia no trabalho docente e da gratificação/punição aos docentes que possuem maior/menor desempenho respectivamente; os salários diferenciados aos professores, no que diz respeito à formação continuada, ao maior/ menor desempenho; as condições e localização de trabalho, entre outros.

Conforme registra o relatório da Unesco, da Comissão Internacional sobre a Educação para o século XXI - Educação: um tesouro a descobrir - acerca da necessidade de melhorar a qualidade da educação, 
[...] é preciso, antes de mais nada, melhorar o recrutamento, a formação, o estatuto social e as condições de trabalho dos professores pois estes só poderão responder ao que deles se espera se possuírem os conhecimentos e as competências, as qualidades pessoais, as possibilidades profissionais e a motivação requeridas. (DELORS, 2006, p. 131).

Nesse contexto, debatem-se diferentes propostas para a formação dos professores, fundadas em projetos políticos e perspectivas históricas diferenciadas, o que faz com que a formação desses profissionais seja tratada ou como elemento impulsionador e realizador dessas reformas, ou como elemento que cria condições para a transformação da própria escola, da educação e da sociedade, sendo que os professores constituem-se elemento chave para qualquer reforma educacional (DELORS, 2006).

Ou seja, a Unesco destaca os professores como a base do sistema educacional, são os fatores determinantes para a obtenção de um dos objetivos estabelecidos no Fórum de Dakar sobre Educação para Todos e reiterado no Fórum de Incheon para promover uma educação de qualidade. Tal desafio confere aos professores grande responsabilidade, no sentido de que se constituam partícipes ativos e comprometidos no desenvolvimento educacional, social, cultural e econômico da humanidade, o que requer que estejam preparados para a atuação profissional. Nessa perspectiva, a Unesco tem atuado com orientações aos países quanto à formação e capacitação de professores no que diz respeito à qualificação de sua atuação, recomendando a atenção aos padrões internacionais definidos nas Conferências/Fóruns quanto ao direito à educação e à formação para a cidadania.

No Relatório de Monitoramento Global de Educação para Todos (UNESCO, 2005), a Unesco pontua recomendações quanto à formação docente, entre elas: a necessidade dos países aprimorarem os processos formativos de professores; da importância do recrutamento e capacitação de docentes para que se mantenham no emprego; da formação de professores para a utilização competente das tecnologias da informação e comunicação, bem como educação a distância.

Ao agir como mecanismo de catalisação de propostas e preconizadora de possibilidades resolutivas para a formação de docentes, a Unesco elege a educação como um bem a ser conquistado por todos/as, potencialmente capaz de desenvolver a sociedade mundial. Nesse sentido, ao reconhecer a centralidade dos docentes nos processos educativos, empreende esforços junto às nações para que sejam realizadas (re)formulações 
educacionais que qualifiquem o contingente de docentes e suas práticas pedagógicas, bem como atendam às necessidades básicas de aprendizagem dos estudantes.

Também, a OCDE tem investido fortemente em recomendações voltadas para a área da educação. Nelas, por exemplo, existe um contingente de atividades realizadas quanto à produção e publicação de sínteses estatísticas relativas aos sistemas educacionais de países integrantes do bloco, sendo o Brasil o único país Latino Americano a participar de todas as edições. Em 1988, a Organização criou o Centro para a Investigação e Inovação Educativa, tornando-se referência mundial em avaliação educacional e, nesse sentido, na produção de indicadores voltados para o desenvolvimento educacional dos países membros.

Nessa perspectiva, surgiu o Programme for International Student Assessment (PISA) - Programa Internacional de Avaliação de Estudantes - o qual considera, na lógica da avaliação comparada e amostral, o rendimento e a conclusão de estudantes matriculados no ensino fundamental. Tal programa realiza avaliação trianual, desde o ano 2000, e prioriza reconhecer as principais necessidades educacionais relacionadas à leitura, ciências e matemática, gerando, entre outros aspectos, indicadores acerca da organização e do funcionamento dos sistemas educativos dos países membros. Além disso, a OCDE, por meio dos indicadores do PISA, apresenta recomendações para a adoção de medidas que minimizem ou combatam as problemáticas evidenciadas, com o objetivo de desenvolvimento da educação de qualidade. Entretanto, tais indicadores tem constituído verdadeiros rankings entre os países.

Considerando a experiência com o PISA, a OCDE criou a Teaching and Learning International Survey (TALIS) - Programa Internacional sobre Ensino e Aprendizagem - referente à produção de dados oriundos do ambiente de aprendizagem e das condições de trabalho dos professores nas escolas em nível mundial. O objetivo é oferecer informações diagnósticas para contribuir com os países na revisão e (re) formulação de políticas educacionais voltadas para o desenvolvimento profissional docente e sua qualificação.

O Brasil, alinhado ao PISA, por meio do Ministério da Educação (MEC), criou o Plano de Ações Articuladas (PAR), em 2007, com a finalidade de diagnosticar o cenário educacional de todos os estados, municípios e distrito federal e, nesse sentido, reconhecer possibilidades para repercutir no aumento do Índice de Desenvolvimento da Educação Básica (IDEB). O Plano tornou-se referência nos entes 
federados, justamente pelo pacto coletivo junto ao Plano de Metas e Compromisso Todos Pela Educação ${ }^{9}$ e pela obrigação de que todos deveriam elaborar seu Plano de Ações Articuladas, especialmente vinculado aos programas e repasses de recursos do governo federal. Foram identificados os principais problemas educacionais e fatores intervenientes no desenvolvimento ou não da educação brasileira. Tais elementos potencializaram ao governo brasileiro e respectivos entes federados uma visão diagnóstica acerca das demandas da educação e, para tanto, impulsionaram na oferta e pactuação de um menu de programas educacionais em regime de cooperação técnica com os entes federados e universidades públicas e privadas de cunho confessional e filantrópico, voltados para a melhoria dos indicadores da educação brasileira.

Para Maués (2009, p. 479), as políticas educacionais: “[...] incidiram fortemente sobre o docente, enquanto protagonista privilegiado do processo educacional. A preocupação com a formação desse profissional passou a ser constante nas agendas dos diferentes países e nas reformas empreendidas [...]" A exemplo, foi publicado em 2006 no Brasil um documento produzido pela OCDE, intitulado Professores são importantes: atraindo, desenvolvendo e retendo professores eficazes, com o objetivo de "[...] fornecer aos formuladores de políticas informações e análises para auxiliar na elaboração e na implementação de políticas para professores que resultem em ensino e aprendizagem de qualidade no nível da escola." (OCDE, 2006, p. 235). Além disso, o documento prioriza: "Sintetizar pesquisas sobre as questões de políticas relacionadas a atrair, recrutar, reter e desenvolver professores eficazes. Identificar iniciativas e práticas políticas inovadoras e bem sucedidas. Facilitar intercâmbio de lições e experiências entre os países." (OCDE, 2006, p. 235). Indicando questões subjacentes à formação e atuação dos professores como “[...] prioritárias para as políticas públicas e o serão cada vez mais nos próximos anos" (OCDE, 2006, p. 7), e que os professores são primordiais no processo de qualificação da educação, constituindo-se “[...] o recurso mais significativo

\footnotetext{
9 De acordo com Camini (2010, p. 537), “O Plano de Metas Compromisso Todos pela Educação, instituído pelo Decreto federal n. 6.094/2007 para ser implementado pela União, tido como o 'carrochefe' (SAVIANI, 2007, p. 3) do PDE, constitui-se em uma estratégia utilizada para regulamentar o regime de colaboração com municípios, estados e Distrito Federal, e com a participação das famílias e da comunidade, visando à mobilização social pela melhoria da qualidade da educação básica. A integração dos entes federados ao Plano é estabelecida através da assinatura de termo de adesão e tal parceria é traduzida 'em compromisso' assumido com a implementação das vinte e oito diretrizes estabelecidas. Da data de lançamento do Plano de Metas Compromisso, em abril de 2007, até final de julho de 2008, o MEC conseguiu que ' $100 \%$ dos municípios brasileiros (5.563) e todos os 26 estados e Distrito Federal aderissem ao compromisso de metas de melhoria da qualidade' (BRASIL, 2008, p. 15)."
} 
das escolas, os professores são fundamentais para os esforços de aprimoramento dessas instituições." (OCDE, 2006, p. 7).

Então, no cenário globalizado, tornou-se realidade a intervenção por meio de “orientações e recomendações" dos organismos internacionais ao governo brasileiro, entre outros países do mundo inteiro, "sugerindo prioridades e (re)formulações educacionais", legitimadas por um discurso ancorado em indicadores, especialmente quantitativos, de que a educação está em crise, que é preciso elevar a qualidade dos serviços educacionais, de que os professores necessitam de formação adequada, de que a gestão não é eficiente, que os currículos não são adequados e contextualizados, de que os insumos precisam ser melhorados e repensados, da necessidade de ampliar o acesso e a permanência tanto na escola quanto na universidade, da in/exclusão social, entre outros aspectos.

Para Campos (2002), análises feitas pelo BM, Cepal e Unesco retratam que existe dissonância entre a educação oferecida pelos sistemas educacionais e a lógica do mercado de trabalho. Nessa perspectiva, as (re)formulações das políticas públicas educacionais implantadas no Brasil passaram a alinhar educação às prioridades e dinâmicas do mercado global, com base nas dimensões de inclusão social, alfabetização, valorização à diversidade e a multiculturalidade, formação profissional, avaliação, intersetorialidade e redes de produção do conhecimento.

Então, a configuração das políticas públicas educacionais do Estado brasileiro, a partir da década de 1990, foram se materializando por meio de decretos, leis, resoluções, entre outros documentos complementares como pareceres, parâmetros e portarias, que se constituíram e se constituem atos normativos e, portanto, marcos orientadores e regulatórios da educação nacional. Nesta lógica, a aprovação da Lei de Diretrizes e Bases da Educação (LDB), Lei n. 9.394, de 1996 (BRASIL, 1996) representou um marco na institucionalização das políticas públicas mais democráticas e propulsora da criação e do desenvolvimento de vários programas educacionais, assim como decretos e resoluções decorrentes para normatizar seus elementos constitutivos que necessitavam de regulamentações mais específicas para atendimento às demandas da educação brasileira.

Após a promulgação da LBD n. 9.394/96, destaca-se os principais encaminhamentos adotados pelo Conselho Nacional de Educação (CNE) no que diz respeito à formação de professores: 
a) Resolução CNE/CP n. 2 (BRASIL, 1997), que se refere aos programas especiais de formação pedagógica de docentes para as disciplinas do currículo do ensino fundamental, do ensino médio e da educação profissional em nível médio, determinando a possibilidade de complementação pedagógica para qualquer graduado/bacharel que queira atuar como professor na educação básica;

b) Resolução CNE ICEB n. 2 (BRASIL, 1999), fundamentada pelo art. 62 da LDB/96, que regulamenta o curso normal em nível médio; a criação dos Institutos Superiores de Educação, específicos para formação de professores para a educação básica;

c) Resolução CNE/CP n. 1 (BRASIL 2002), que institui Diretrizes Curriculares Nacionais para a Formação de Professores da Educação Básica, em nível superior, curso de licenciatura, de graduação plena;

d) Decreto n. 6.755/2009, instituindo a Política Nacional de Formação de Profissionais do Magistério da Educação Básica;

e) Resolução CNE/CP n. 2/2015 (BRASIL, 2015), instituindo as Diretrizes Curriculares Nacionais para a formação inicial em nível superior e para a formação continuada e revogando a Resolução CNE ICP n. 1/2002;

f) Decreto n. 8.752/2016 (BRASIL, 2016), instituindo a Política Nacional de Formação dos Profissionais da Educação Básica e revogando o Decreto n. 6.775/2009;

g) Diretrizes Curriculares específicas alusivas aos cursos de licenciaturas, a exemplo da Resolução CNE/CP n. 1 de 2006 (BRASIL, 2006), instituindo Diretrizes Curriculares para o Curso de Pedagogia.

Esses marcos regulatórios, entre outros, passaram a incidir diretamente na concepção e arquitetura das políticas e ações educacionais no âmbito da união e entes federados, com íntimo alinhamento às orientações dos organismos internacionais. Surgiram mudanças no cenário educacional que alteraram o formato de administração pública, a relação entre escola e universidade, a concepção de tempo e aula/formação presencial e a distância e, consequentemente, os processos de formação dos profissionais da educação os quais se tornaram importante estratégica para a concretização das (re) formulações educacionais do governo brasileiro. Tais documentos regulamentadores 
da educação nacional fundamentaram a (re)formulação das políticas de formação de professores no Brasil, em níveis macro e micro, o que repercutiu em programas e ações do governo federal, entre os quais Dalla Corte e Sarturi (2015a) destacam:

a) a Rede Nacional de Formação Continuada de Professores, que surgiu em 2004, com a finalidade de articulação da formação continuada à pesquisa e, consequentemente, à produção acadêmica desenvolvida nas Universidades;

b) o Pró-Licenciatura, criado em 2005, relacionado à formação inicial a distância de professores em serviço, que se utilizou de estudos referentes às fragilidades da formação dos docentes atuantes no ensino fundamental e médio;

c) a Universidade Aberta do Brasil (UAB), criada pelo Decreto n. 5.622 de 2005, que priorizou ampliar a oferta da formação superior em nível de graduação e pós-graduação (lato sensu). A UAB, no que tange à formação dos profissionais da educação, focou nos docentes que atuam na educação básica, nas equipes diretivas, nos dirigentes municipais, entre outros;

d) o Programa de consolidação das Licenciaturas - Prodocência, criado em 2007, com a finalidade de desenvolver projetos institucionais referentes à gestão educacional/escolar, focando em experiências metodológicas e práticas inovadoras, cooperação técnica entre a universidade e demais contextos educativos (escolares e não escolares);

e) na perspectiva do Decreto n. 6.755/2009, a Política Nacional de Formação de Profissionais do Magistério da Educação Básica disciplinando a atuação da Coordenação de Aperfeiçoamento de Pessoal de Nível Superior (CAPES) no fomento a programas de formação inicial e continuada, entre os quais se destaca o Programa 
Institucional de Bolsa de Iniciação à Docência $\left(\operatorname{PIBID}^{10}\right)$ e $\mathrm{o}$ Observatório da Educação; ${ }^{11}$

f) o Plano Nacional de Formação de Professores da Educação Básica (PARFOR), instituído para atender o Decreto n. 6.755, de 29 de janeiro de 2009, priorizou atender às demandas e ações de formação inicial e continuada do MEC, em sintonia e regime de cooperação técnica com as Secretarias Estaduais e Municipais de Educação, assim como as Instituições de Educação Superior (IES) com a responsabilidade de ministrar os cursos de licenciatura aos professores (lotados nas redes públicas) e que não possuem formação em nível de graduação;

g) o Programa de Apoio a Planos de Reestruturação e Expansão das Universidades Federais (REUNI), instituído pelo Decreto n. 6.096, de 24 de abril de 2007, como uma das ações que integram o Plano de Desenvolvimento da Educação (PDE). É um programa que repercutiu na expansão dos cursos de licenciatura pelas universidades federais, considerando os seguintes fatores decorrentes de sua execução: a interiorização das universidades; a expansão de cursos noturnos; a ampliação do menu dos cursos de graduação pelas IES, novos concursos para docentes e técnicos administrativos, ampliando o contingente de recursos humanos; ampliação da oferta de vagas nos cursos de graduação; o aumento do número de matrículas; a ampliação dos espaços físicos nas Universidades Federais com novas obras; expansão do número de campi e municípios atendidos; ampliação de bolsas de Assistência ao Ensino incluindo docentes e discentes.

\footnotetext{
10 Um programa criado pelo Decreto n. 7.219/2010. Em sua lógica, os partícipes (alunos e docentes dos cursos de licenciatura, professores coordenadores na IES e professores supervisores nas escolas das redes públicas) são bolsistas CAPES, os quais têm o compromisso de trabalhar compartilhadamente tanto na universidade quanto nos espaços escolares. Sua finalidade primeira está justamente fundada na lógica de fomentar a iniciação à docência e qualificá-la, objetivando repercussões diretas na melhoria do desempenho da educação básica (DALLA CORTE; SARTURI, 2015a).

11 Tem por objetivo fomentar estudos e pesquisas em educação que utilizem a infraestrutura disponível das Instituições de Educação Superior (IES) e as bases de dados existentes no INEP. O programa visa, principalmente, proporcionar a articulação entre pós-graduação, licenciaturas e escolas de educação básica e estimular a produção acadêmica e a formação de recursos para pós-graduados, em nível de mestrado e doutorado (BRASIL, 2008).
} 
As autoras acrescentam outras ações e programas de governo em atendimento à Política Nacional de Formação dos Profissionais da Educação no Brasil:

[...] a) Formação superior de professores em exercício: $1^{\text {a }} \mathrm{Li}$ cenciatura para professores da rede pública sem curso de graduação; $2^{\text {a }}$ Licenciatura para professores que atuam em disciplinas fora de suas licenciaturas; Formação pedagógica para professores com graduação, mas sem licenciatura; Formação pedagógica para bacharéis; Cursos de Especialização (presencial, semipresencial e a distância); Mestrados Profissionais, entre outros. b) Redes de capacitação e formação continuada: Pró-Infantil; Educação Inclusiva - Direito à Diversidade; Proinfo; Pró-letramento - Linguagens e Matemática (atual Pacto Nacional pela Idade Certa); Programa Gestar - Português e Matemática; Pró-Conselho; Pradime; Formação de Conselheiros Escolares; Programa Escola Ativa, entre outros programas. (DALLA CORTE; SARTURI, 2015b, p. 166).

Para tanto, na perspectiva das ações do governo federal brasileiro, o regime de cooperação técnica com os entes federados e Instituições de Ensino Superior tornouse uma estratégia presente no período de 2003 a 2016, especialmente na vigência dos governos Lula e Dilma, com o investimento em programas e ações que potencializassem o acesso à formação (inicial e continuada) dos profissionais da educação, em especial, dos professores e futuros professores atuantes na educação básica.

As reformulações preconizadas pelos organismos multilaterais, nas últimas décadas, certamente interferiram nas definições e encaminhamentos realizados pelo governo brasileiro, na perspectiva de que os docentes em serviço e os futuros docentes entre outros atores do cenário educacional, a exemplo dos conselheiros de educação, dirigentes municipais, conselheiros escolares, pudessem participar de momentos de formação e assumir protagonismo no processo da reforma educacional, já que os documentos mundiais produzidos pelo BM, pela Unesco e a OCDE apontam que a qualidade da educação não é possível sem bons docentes.

As políticas educacionais produzidas pela lógica do capital mundial desafiam e alteram a lógica das políticas e gestão educacional no Brasil e, consequentemente, o formato dos processos formativos de professores e o perfil desses profissionais, ainda entendidos como mecanismos para as metas e indicadores da economia mundial. 


\section{A FORMAÇÃO DE PROFESSORES E O DESENVOLVIMENTO PROFISSIONAL}

Tratar da formação específica para a docência ainda se faz emergente na atualidade em função de que, no Brasil, temos uma escassa formação para ser professor nesse âmbito, que contemple a complexidade da docência, dada a relação indissociada entre o ensino, a pesquisa e a extensão, que requer do professor competências e habilidades que possibilitem interagir, dialogar, refletir, sistematizar e se relacionar conhecimentos, saberes e fazeres em diversos e diferentes espaços institucionais.

A formação de professores é parte do desenvolvimento profissional docente, que conforme, Marcelo e Vaillant (2010, p. 153) apontam que "[...] el desarrollo profesional ha de asumirese entonces como na plataforma de proyección de la profesión docente hacia del nuevos e complejos enscenarios de nuestras sociedades."

Assim, a prática formativa necessita agregar habilidades que implicam na prática docente mobilizada pela constante circularidade de ações reflexivas sobre a docência, no sentido de aprender como se desenvolve os processos de ensino e de aprendizagem, compreendidos como uma ação complexa, envolvendo o todo e as partes. Esse processo formativo requer uma estrutura de formação profissional que dê conta de toda a trajetória profissional, por meio de ações vivenciadas e reflexivas, permeado por uma atenção, em relação a vários aspectos da docência, que vai desde o planejamento macro da disciplina/série até a organização da aula, a seleção de material, a gestão do tempo da aula, o desenvolvimento das atividades educativas e a avaliação.

Cunha e Zanchet (2010, p. 25) definem "[...] a docência como uma atividade complexa, exige tanto uma preparação cuidadosa como singulares condições de exercício." Frente às demandas da docência e a complexidade da mesma, entendese que é necessário pensar em propostas formativas colaborativas e ancoradas na conjuntura e demandas do contexto educacional, para que essa formação tenha um impacto e efetivamente contribua na construção da identidade docente e desencadeie o desejo da participação efetiva na trajetória formativa.

Nesse sentido, a formação continuada necessita ser dinâmica, flexível e organizada de forma que os professores se sintam apoiados e protagonistas em um verdadeiro processo da auto/formação; nessa lógica, a formação não pode ser estanque, demarcada somente pelos encontros estruturados na organização da programação, sobretudo, precisa de uma articulação que desencadeie ações formativas reflexivas em 
grupos de discussões permanentes. Esses grupos de discussões, podem se configurar em comunidades de aprendizagens, sendo uma estratégia formativa, que propicia que a formação rompa as fronteiras dos encontros nos grandes grupos, geralmente desenvolvidos nas práticas de formação. Para Cunha (2014), as comunidades de aprendizagem são grupos que se formam a partir de uma liderança partilhada com a assessoria pedagógica, para diagnosticar e refletir sobre as realidades, sobre o aprofundamento de questões teóricas; de temas mobilizadores; de experiências profissionais; de partilha, e realimentá-las para contribuir com seus colegas e com o campo de conhecimento em que atuam. Essa ideia permeou a proposição de alguns programas de governo, voltados para a formação docente, entretanto é preciso aproximar os elementos teóricos e legais das práticas formativas e contextuais.

Entende-se que a formação precisa estar respaldada na vivência do professor, estruturada a partir das necessidades reais provenientes da prática docente, para que efetivamente possa contribuir e desencadear o desenvolvimento profissional e a construção da identidade docente, fortalecendo e qualificando sua atuação docente na perspectiva de formação ao longo da vida. Conforme destaca Marcelo e Vaillant (2010, p. 79): “El proceso de formación tiende a definirse como un conjunto, y se pone el acento en las necesidades que se suceden en distintas etapas de la vida profesional', dessa forma o professor necessita ter o entendimento sobre processo formativo, demarcado no início da carreira e projetado para ser desenvolvido ao longo da trajetória profissional.

A autoformação é uma formação na qual o indivíduo participa independentemente e tem sob seu controle os objetivos, os processos os instrumentos e os resultados da própria formação. A heteroformação se organiza e se desenvolve "de fora", por especialistas, sem que seja comprometida a personalidade do sujeito que dela participa. Por último, a interformação se refere à formação que se produz em contextos de trabalho em equipe (VAILLANT; MARCELO, 2012, p. 30). O "modelo" de formação continuada priorizado e desenvolvido pelo governo brasileiro vem historicamente se constituindo na perspectiva da "heteroformação", ou seja, de fora para dentro.

Vaillant e Marcelo (2012) reafirmam a necessidade da formação de interrelacionar os conhecimentos prévios com as práticas vivenciadas pelos professores e, nesse sentido, complementam que "[...] as experiências são mais eficazes quando permitem que os docentes relacionem as novas experiências com seus conhecimentos 
prévios [...] Diferentemente das práticas tradicionais de formação, que não relacionam as situações de formação com as práticas de sala de aula.” (VAILLANT; MARCELO, 2012, p. 196). Talvez esse seja o maior desafio junto aos programas de governo que possuem conteúdos específicos a serem trabalhados na formação dos docentes, entretanto, ainda, mantêm-se distantes das necessidades do cotidiano escolar. Nessa perspectiva, o processo formativo precisa emergir das necessidades dos professores, como também reafirmam Bolzan, Isaia e Maciel (2013, p. 53): “[...] a formação de professores pressupõe a organização de um processo contínuo e sistemático que considere as exigências sociais, psicológicas, pessoais, contextuais e profissionais como parte do desenvolvimento profissional docente."

Embora já tenham pesquisas sobre o processo de autoformação, constatase que ainda é necessário avançar no sentido da aplicabilidade dessa formação ao desenvolver estratégias formativas que deem conta da autoformação e interformação, no sentido de agregar os dois tipos. Marcelo (2002) reafirma a necessidade de se ter uma formação específica para o professor desde a entrada da carreira, pois não podemos esperar que a formação profissional inicial dê conta de toda a trajetória profissional; pelo contrário, as transformações profissionais requerem uma atitude de permanente aprendizagem.

É emergente que as políticas públicas educacionais no Brasil tenham em sua essência essa concepção mais presente, no sentido de repercutir na realização de estratégias formativas de assessoramento pedagógico direto às comunidades escolares; que mobilizem de uma forma dinamizadora o processo formativo permanente de professores, a fim de que seja caracterizado por um espaço de aprendizagem significativa para o exercício da profissão docente. Para Lucarelli (2004, p. 38), o assessoramento pedagógico se caracteriza pela interação do assessor pedagógico na atitude protagonista em relação a:

\footnotetext{
Posibilidad de consulta pedagógica que beneficie el trabajo interdisciplinario y la búsqueda de un aprendizaje significativo; orientación teórico-pedagógica; apoyo técnico; soluciones previstas para problemas detectados; desarrollo de un trabajo conjunto con los docente para el abordaje pedagógico; orientaciones teórico-prácticas sobre situaciones puntuales.
}

O professor que exerce o papel de assessor pedagógico prioriza a dinamização, problematização e reflexão acerca do cotidiano da atuação docente, no sentido de potencializar a auto/formação do professor participante. Nesse sentido, os 
protagonistas desse processo formativo envolvem-se nas interações dinamizadas no assessoramento pedagógico, a fim de construírem o conhecimento e (re)construírem sobre a docência, a fim de (re)significá-la, ampliá-la e qualificá-la. Essas interações geram uma aprendizagem coletiva e compartilhada, a partir das situações dialógicas e emergentes do cotidiano.

Um dos princípios para o processo formativo continuado é a aprendizagem mútua se configurando em um benefício para todos. Para Moreno e Mayor (1999, p. 170): “[...] el proceso de asesoramiento profesor reporta beneficios a todos los participantes inmersos en el mismo: profesor e instituciones educativas que apoyan el desarrollo de este proceso." Assim, o assessoramento pedagógico precisa apoiar a reflexão sobre a prática e demarcar o lugar de formação, carregada pelas subjetividades dos professores que compartilham ideias, estabelecem as bases de socialização profissional, configurando-se por ser o embrião para o profissionalismo interativo. Assessoramento pedagógico, visto como estratégia no processo formativo, requer ações que deem conta da complexidade da docência mencionada pelos diferentes pesquisadores e precisa ser visto como uma "oportunidade de aprender a docência", desencadeando nos professores reflexões referentes ao cotidiano da profissão, as quais envolvem os saberes e fazeres docentes.

Vaillant e Marcelo (2012) enfatizam que o desenvolvimento profissional é, antes de tudo, uma aprendizagem que deve brindar oportunidades aos professores de aprender em situações práticas de como se ensina. A complexidade da docência acontece também no sentido de que o professor tem demandas que estão além do ensino, são demandas administrativas, que são vitais à organização da instituição, além das demandas sociais que interferem no cotidiano escolar. Conforme destacam Vaillant e Marcelo (2012, p. 169): “O desenvolvimento profissional docente implica em interação com os contextos espacial e temporal. [...] Dessa forma, as condições de trabalho influenciam no desenvolvimento profissional docente, promovendo-o ou inibindo-o." Para os autores, os programas de formação docente necessitam ser organizados de maneira que impulsionem a reflexão sobre a prática, fazendo com que o próprio professor identifique suas necessidades, organizando sua formação para suprir tal necessidade. Além disso, os programas precisam reservar um tempo para os professores dinamizarem suas estratégias de ensino na sala de aula, apoiados pelos formadores, para fins de enfrentar suas dificuldades, ou seja, um programa eficaz precisa estimular os professores a "narrar e refletir" sobre suas práticas, de forma que 
possam transformá-la a partir da conscientização das problemáticas, das prioridades e do estabelecimento de estratégias apropriadas para cada situação, gerando, portanto, auto/trans/formação na atuação docente.

\section{4 (IN)CONCLUSÕES}

A ênfase atribuída pelas Conferências/Fóruns Mundiais e organismos internacionais quanto à formação e papel dos professores, tornou-se catalizadora de propostas e (re)formulações de políticas públicas educacionais no Brasil nas três últimas décadas. Tais orientações são disseminadoras de encaminhamentos que direcionam os países a estabelecer prioridades educacionais. Entretanto, apesar de tais organismos e Conferências/Fóruns estabelecerem orientações, não basta para que possamos de fato atender às necessidades formativas dos profissionais da educação. Não basta colocar à disposição das redes de ensino, em regime de cooperação técnica com secretarias e IES, um vasto menu de programas de formação docente se, ao mesmo tempo, as condições de acesso, permanência e sucesso, ainda, são muito frágeis. Participar de um curso e concluir o mesmo (seja de capacitação, de graduação ou pós-graduação) não é sinônimo de qualidade educacional.

Nessa lógica, defende-se que os programas de governo voltados para a formação continuada dos profissionais da educação, além de priorizarem a oferta, o acesso e materiais de estudo, tem de estar em sinergia com as reais condições das redes de ensino, entre eles, focar em qualificar: as condições de trabalho dos docentes em serviço; as possibilidades de carga horária dos docentes para participação efetiva dos cursos oferecidos; o planejamento contextualizado e compartilhado acerca dos conteúdos, estudos e atividades a serem desenvolvidas; e as IES utilizando seu contingente de professores formadores com experiência na educação básica, para que possam estabelecer efetiva interlocução com os docentes em serviço, entre outras prioridades.

Não basta, portanto, criar decretos, resoluções, programas, bem como marcos normativos que definam, determinem e resolvam o que o cenário educacional brasileiro deverá contemplar; tais ações acabam se esvaziando justamente pelo distanciamento da teoria e a legislação com o contexto na prática. A exemplo das orientações dos organismos multilateriais que são, de fato, importantes e decisivas para a melhoria da qualidade educacional nos diversos países envolvidos, o deslocamento dos documentos decorrentes de tais orientações para as práticas e processos formativos 
no ideário dos sistemas educacionais no Brasil, entretanto, tem se constituído um enorme desafio para a sua consecução.

Os professores são essenciais para a promoção da educação de qualidade e as reformas educacionais se constituírem bem sucedidas. As (re)formulações nas políticas educacionais requerem professores qualificados e protagonistas no cenário da educação básica e superior, porém é preciso começar a inverter a lógica verticalizada e histórica de formulação e consecução das políticas educacionais no Brasil, no entendimento de que se houver o olhar no contexto microeducacional em suas minúcias, talvez, se torne possível atender efetivamente as necessidades formativas dos docentes e qualificá-los em seus reais contextos de atuação profissional. Caso contrário, o ideário da política global de formação de professores compensatória terá continuidade, visando somente atender aos ditames da lógica de mercado, e que não potencializa o real investimento nas prioridades locais, esvaziando-se em si mesma.

Outro aspecto importante e que é preciso atenção, diz respeito às prioridades e orientações mundiais que envolvem ajuda internacional, em especial de países desenvolvidos, os quais objetivam, entre outros aspectos, manter a relação colonialista de produção e circulação de mercadorias, em especial no que se refere aos produtos tecnológicos. Tal lógica implica na acumulação de capital desses países desenvolvidos, justamente porque são os principais produtores dessas mercadorias e suas patentes.

Nesse sentido, as políticas subjacentes às (re)reformações educacionais, desde a década de 1990 no Brasil, estão em consonância com as orientações de organismos multilaterais, e que as mesmas (re)definiram o papel do Estado brasileiro e dos entes federados, assim como da relação entre educação básica e educação superior, no que diz respeito à formação dos profissionais da educação. Tais políticas têm privilegiado o privado, no sentido de tornar consenso a concepção de Estado mínimo no que diz respeito à manutenção das áreas sociais, entre elas a educação. Essa perspectiva requer ações coletivas, mas que descentralizam o papel da União, que passa a atribuir responsabilidades aos Estados, Municípios e Distrito Federal, em especial às universidades, como gestoras e formadoras junto aos programas de governo, para além da formação inicial de professores, desencadeando a inexistência de limite entre o público e o privado.

É necessária a busca pelo avanço do entrelaçamento das políticas públicas com as propostas formativas institucionalizadas para a constituição de processos formativos permanentes, que tenham impacto no desenvolvimento profissional 
docente, alicerçado nas vivências pedagógicas significativas demarcadas pelas conexões promovidas pela interação entre os participantes. Pois, ainda é perceptível que, algumas vezes, o processo de aprendizagem da docência é estabelecido pelo ensaio e erro, por um processo intuitivo e informal, como se aprender a profissão docente fosse a simplicidade de agregar experiências de sala de aula já vividas no processo acadêmico, aliado ao desejo do professor em acertar.

Desse modo, é emergente pensar no movimento do processo formativo para uma rede reflexiva de saberes, que crie dispositivos práticos e auto/trans/formativos, para que se desencadeie o protagonismo no processo de aprendizagem da docência básica e universitária frente aos desafios provenientes do cenário educacional atual.

As políticas de formação docente necessitam, de fato, enfatizar a formação e a aprendizagem ao longo da trajetória profissional, em que se configura por uma ação formativa permanente, necessária para qualificar e valorizar os professores, para que não aconteça de maneira isolada, sem uma política com diretrizes pré-estabelecidas para orientar o processo formativo.

Em síntese, defende-se a importância da existência de políticas públicas voltadas à formação dos profissionais da educação, em especial os docentes que estão em sala de aula. Entretanto, tais políticas requerem ser desenvolvidas por meio de ações que, para além de normalizar e atender "recomendações" globais em sintonia ao projeto neoliberal, possam realmente contribuir para a qualificação e melhorias do ensino e da aprendizagem na educação básica e superior.

\section{REFERÊNCIAS}

AZEVEDO, J. M. L. de; AGUIAR, M. A. A produção do conhecimento sobre a política educacional no Brasil: um olhar a partir da ANPED. Educação \& Sociedade, v. 22, n. 77, dez. 2001.

BALL, S. Performatividade e fabricações na economia educacional: rumo a uma sociedade performativa. Educação e Realidade, v. 35, n. 2, p. 37-55, ago./set. 2010a.

BALL, S. Vozes/redes políticas e um currículo neoliberal global. Espaço do Currículo, v. 3, n. 1, 2010 b.

\section{BANCO MUNDIAL. Mejorar la enseñanza y el aprendizaje por médio de} incentivos: qué lecciones nos entregan las reformas educativas de América Latina? Washington, 2005. 
BANCO MUNDIAL. Prioridades y estrategias para la educacion: examen del Banco Mundial. Washington, 1995.

BRASIL. Conselho Nacional de Educação. Conselho Pleno. Resolução CNE/CP n. 1, de 15 de maio de 2006. Institui as Diretrizes Curriculares Nacionais para o curso de graduação em Pedagogia, licenciatura. Diário Oficial da União, Brasília, DF, 16 maio 2006.

BRASIL. Conselho Nacional de educação. Resolução CNE/CP n. 1, de 18 de fevereiro de 2002. Institui Diretrizes Curriculares Nacionais para a formação de professores da educação básica, em nível superior, curso de licenciatura de graduação plena. Brasília/DF, 2002. Disponível em: <http://portal.mec.gov.br/seesp/arquivos/ pdf/res1_2.pdf>. Acesso em: 10 dez. 2016.

BRASIL. Conselho Nacional de Educação. Resolução CNE/CEB n. 2, de 19 de abril de 1999. Institui Diretrizes Curriculares Nacionais para a Formação de Docentes da Educação Infantil e dos anos iniciais do Ensino Fundamental, em nível médio, na modalidade Normal. Brasília, DF, 1999.

BRASIL. Conselho Nacional de Educação. Resolução CNE/CP n. 2, de 01 de julho de 2015. Institui Diretrizes Curriculares Nacionais para a formação inicial em nível superior (cursos de licenciatura, cursos de formação pedagógica para graduados e cursos de segunda licenciatura) e para a formação continuada. Disponível em: $<$ http://ced.ufsc.br/files/2015/07/RES-2-2015-CP-CNE-Diretrizes-Curriculares-Nacionais-para-a-forma $\% \mathrm{C} 3 \% \mathrm{~A} 7 \% \mathrm{C} 3 \% \mathrm{~A} 30$-inicial-em-n $\% \mathrm{C} 3 \% \mathrm{ADv}$ - - superior. pdf>. Acesso em: 19 set. 2016.

BRASIL. Conselho Nacional de Educação. Resolução CNE/CP n. 2, de 26 de junho de 1997. Que dispõe sobre os Programas Especiais de Formação Pedagógica de Docente para as disciplinas do currículo do Ensino Fundamental e do Ensino Médio e da educação profissional em Nível Médio. Brasília, DF: CNE, 1997.

BRASIL. Decreto n. 6.094, de 24 de abril de 2007. Dispõe sobre a implementação do Plano de Metas Compromisso Todos pela Educação, pela União, em regime de colaboração com municípios, Distrito Federal e Estados. Diário Oficial da União, Brasília, DF, 24 abr. 2007.

BRASIL. Decreto n. 6.755, de 29 de janeiro de 2009. Institui a Política Nacional de Formação de Profissionais do Magistério da Educação Básica, disciplina a atuação da Coordenação de Aperfeiçoamento de Pessoal de Nível Superior - CAPES. Diário Oficial da União, Brasília, DF, 30 jan. 2009. Disponível em: <http://www.planalto. gov.br/ccivil_03/_ato2007-2010/2009/decreto/d6755.htm>. Acesso em: 21 out. 2016. 
BRASIL. Decreto n. 8.752, de 9 de maio de 2016. Institui a Política Nacional de Formação dos Profissionais da Educação Básica. Diário Oficial da União, Brasília, DF, 10 maio 2016. Disponível em: <http://www.planalto.gov.br/ccivil_03/_Ato20152018/2016/Decreto/D8752.htm>. Acesso em: 21 out. 2016.

BRASIL. Lei n. 9.394, de 23 de dezembro de 1996. Estabelece as Diretrizes e Bases da Educação Nacional. Diário Oficial da União, Brasília, DF, 23 dez. 1996.

BRASIL. Ministério da Educação. Fundação Capes. PROGRAMA OBSERVATÓRIO DA EDUCAÇÃO. 2008. Disponível em: < http://www.capes.gov.br/educacao-basica/observatorio-da-educacao>. Acesso em: 18 dez. 2016.

BOLZAN, D.; ISAIA, S.; MACIEL, A. M. da R. Formação de professores: a construção da docência e da atividade. Revista Diálogo Educacional, Porto Alegre, v. 13, p. 49-68, 2013.

CAMINI, L. A política educacional do PDE e do Plano de Metas Compromisso Todos pela Educação. RBPAE, v. 26, n. 3, p. 535-550, set./dez. 2010. Disponível em: <http://www.seer.ufrgs.br/rbpae/article/viewFile/19797/11535>. Acesso em: 28 set. 2016.

CAMPOS, R. F. A reforma da formação inicial dos professores da educação básica nos anos de 1990 - desvelando as tessituras da proposta governamental. 2002. 232 p. Tese (Doutorado em Educação)-Universidade Federal de Santa Catarina, Florianópolis, 2002.

CAMPOS, R. F. O cenário da formação de professores no Brasil - analisando os impactos da reforma da formação de professores. In: REUNIÃO NACIONAL DA ANFOPE, 12., Brasília, DF. Anais... Brasília, DF, 2004.

CUNHA, M. I. Estratégias institucionais para o desenvolvimento profissional docente e as assessorias pedagógicas universitárias: memórias, experiências, desafios e possibilidades. São Paulo: Junqueira \& Marin, 2014.

CUNHA, M. I.; ZANCHET, B. M. A problemática dos professores iniciantes: tendência e prática investigativa no espaço universitário. Revista Educação, Porto Alegre, v. 33, n. 3, p. 189-197, set./dez. 2010. Disponível em: <http://revistaseletronicas.pucrs.br/ojs/index.php/faced/article/viewFile/6999/5717 >. Acesso em: 21 set. 2016.

DALLA CORTE, M. G.; SARTURI, R. Políticas públicas para a formação de professores e contextos emergentes na educação superior. Revista Internacional de Educação Superior, Campinas, v. 1, n. 2, p. 160-181, out./dez. 2015b. Disponível em: <http://ojs.fe.unicamp.br/ged/RIESup/article/view/7430/6220>. Acesso em: 27 ago. 2016. 
DALLA CORTE, M. G.; SARTURI, R. Visão Panorâmica de indicadores e políticas públicas subjacentes à formação de professores no Brasil. In: ALMEIDA, M. L. P.; BONETI, L. W.; PACIEVITCH, T. Políticas Educacionais e Docência na Contemporaneidade. Curitiba: CRV, 2015a. p. 35-58.

DELORS, J. (Org.). Educação um tesouro a descobrir. Relatório para a Unesco da Comissão internacional para o século XXI. 10 ed. São Paulo: Cortez; Brasília, DF: MEC: UNESCO, 2006.

EVANGELISTA, O.; MORAES, M. C. M.; SHIROMA, E. O. Política Educacional. Rio de Janeiro: DP\&A, 2002.

LUCARELLI, E. (Org.). EI asesor pedagógico em la universidad: de la teoria pedagógica a la prática em la formación. Buenos Aires: Paidós, 2004.

MACIEL, L. S. B.; NETO, A. S. As políticas neoliberais e a formação de professores: propostas de formação simplistas e aligeiradas em épocas de transformação. In: MACIEL, L. S. B.; NETO, A. S. (Org.) Formação de Professores: passado, presente e futuro. São Paulo: Cortez, 2004.

MARCELO, C. Los profesores como trabajadores del conocimiento. Educar, v. 3, p. 27-56, 2002.

MARCELO, C.; VAILLANT, D. Desarrollo Profesional Docente: como se aprende a enseñar? Madrid: Narcea, 2010.

MAUÉS, O. C. A política da OCDE para a Educação e a formação. In: ENCONTRO DE PESQUISA EDUCACIONAL DO NORTE E NORDESTE (EPNN), 19., 2009, João Pessoa. Anais... Rio de Janeiro: ANPEd, 2009.

MORENO, M.; MAYOR, C. R. Los equipos docentes: una contribuición formativa a la calidad del professorado universitario. Revista de Educación, Universidad de Huelva, 1999, p. 157-176. Disponível em: < http://rabida.uhu.es/dspace/bitstream/ handle/10272/306/b11505485.pdf?sequence=1>. Acesso em: 04 dez. 2016.

NOGUEIRA, E. S. Políticas de formação de professores: a formação cindida (1995 - 2002). 2003. 198 p. Tese (Doutorado em Educação)-Universidade Federal do Rio de Janeiro, Rio de Janeiro, 2003.

ORGANIZAÇÃO PARA COOPERAÇÃO E DESENVOLVIMENTO ECONÔMICO. Professores são importantes. Atraindo, desenvolvendo e retendo professores eficazes. São Paulo: Coedição Moderna: OCDE, 2006. 
SILVA JÚNIOR, J. dos R. Mudanças estruturais no capitalismo e a política educacional do governo FHC: o caso do ensino médio. Educação \& Sociedade, Campinas, v. 23, n. 80, P. 201-233, set. 2002.

UNESCO. Organização das Nações Unidas para a Educação, Ciência e Cultura. Declaração de Incheon. Educação 2030: rumo a uma educação de qualidade inclusiva e equitativa e à educação ao longo da vida para todos. Incheon, China: Cúpula Mundial de Educação, 2015. Disponível em: <http://unesdoc.unesco.org/ images/0023/002331/233137POR.pdf>. Acesso em: 10 dez. 2016.

UNESCO. Organização das Nações Unidas para a Educação, Ciência e Cultura. Declaração Mundial de Educação para Todos. Jomtien, Tailândia: Cúpula Mundial de Educação, 1990. Disponível em: <http://unesdoc.unesco.org/ images/0008/000862/086291por.pdf/>. Acesso em: 10 dez. 2016.

UNESCO. Organização das Nações Unidas para a Educação, Ciência e Cultura. O Marco de Ação de Dakar Educação Para Todos: atendendo nossos Compromissos Coletivos. Dakar, Senegal: Cúpula Mundial de Educação, 2000. Disponível em: $<$ http://unesdoc.unesco.org/images/0012/001275/127509porb.pdf > . Acesso em: 10 dez. 2016.

UNESCO. Organização das Nações Unidas para a Educação, Ciência e Cultura. Relatório de Monitoramento Global de Educação para Todos. 2005. Disponível em: <http://unesdoc.unesco.org/images/0013/001390/139079por.pdf $>$. Acesso em: 03 out. 2016.

VAILLANT, D.; MARCELO, C. Ensinando a ensinar: as quatro etapas de uma aprendizagem. Curitiba: UTFPR, 2012.

Endereço para correspondência: Av. Roraima, 1000, Camobi, Santa Maria, 97105900, Rio Grande do Sul, Brasil; 